\title{
Possible role of RAGE and ER expression in therapy of bladder cancer
}

\author{
Tarek Aboushousha $^{1 *}$, Olfat Hammam ${ }^{1}$, Amr Abdelnasser ${ }^{2}$, Ahmed Montasser ${ }^{1}$ and Hani Nour $^{3}$ \\ ${ }^{1}$ Pathology Department, Theodor Bilharz Research Institute, Cairo, Egypt \\ ${ }^{2}$ Faculty of Biotechnology, October University for Modern sciences and Arts, Giza, Egypt \\ ${ }^{3}$ Urology Department, Theodor Bilharz Research Institute, Cairo, Egypt
}

\begin{abstract}
Introduction: Each year, 430,000 people are diagnosed with bladder cancer. Certainly, suitable diagnostic and therapeutic markers are required to improve the detection and treatment of bladder cancer and hence to prolong survival of patients. Receptor for advanced glycation end products (RAGE) is a multi-ligand receptor that is present on cells of the monocyte or macrophage lineage and cells of vascular origin. It is highly expressed and associated with inflammations related to pathological states such as cancer.

Estrogen receptor (ER) is one of large family member of nuclear receptor transcription factors. They are the main responsible for growth of estrogen responsive tumors such as; endometrial and breast cancers. Estrogen plays a role in bladder development and homeostasis and has been implicated in more advanced stage bladder tumors.

Methods: We evaluated the expression of RAGE and ER on 58 bladder cancer tissue sections by immunohistochemical method.

Results: RAGE expression was significantly higher in bladder cancer compared to cystitis and in non-papillary high grade tumors with muscle invasion compared to their counterparts. On the other hand, ER expression was higher in cases of urothelial carcinoma compared to cases of cystitis and in papillary low grade non-invasive tumors than in their counterparts. No significant differences were achieved for both RAGE and ER expression between bilharzial and non-bilharzial associated bladder cancer.
\end{abstract}

Conclusion: We concluded that RAGE and ER are potential biomarkers that may be targets for molecular based therapeutic strategies in the management of bladder cancer.

\section{Introduction}

Carcinoma of the bladder is a worldwide health problem. It is the seventh most commonly diagnosed cancer in the male population worldwide. It drops to eleventh when both genders are considered, with more than 430,000 case diagnosed every year around the world [1].

Histologically, bladder cancer is divided into urothelial (90-95\%) [2] and non-urothelial (5-10\%) types. Transitional cell carcinoma (TCC) is the most common form of urothelial bladder cancer ( $\approx 90 \%)$ followed by the squamous cell type $(\approx 10 \%)$. Adenocarcinoma represents less than $1 \%$ of urothelial bladder cancer. Squamous cell carcinoma accounts for about $40 \%$ of bladder cancer in Egypt and usually associated with chronic infection by Schistosoma haematobium worm [3]. Tobaco smoking is the most important risk factor for development of TCC. Industrial exposure to aromatic amines, polycyclic aromatic hydrocarbons and chlorinated hydrocarbons is the second most important risk factor [4]. Chronic shistosomal infestation represents the most important risk factor for development of squmous cell carcinoma [3]. Haematuria is the most common presenting symptom of bladder cancer, yet it's neither sensitive nor specific for the disease [5]. The diagnosis of bladder cancer relies on pathological examination of tumor tissue following endoscopic resection. Despite high specificity, urine cytology is not sensitive for the diagnosis of bladder cancer, yet it is widely used for following up [6]. Patients' prognosis following definitive treatment depends on histological type, pathological stage, and tumor grade. Several tissue markers have been studied to enhance the prognostic accuracy, but the results are conflicting [7]. Certainly, suitable molecular diagnostic markers are required for the detection of bladder cancer improvement and then to delay survival of patients [8].

Receptor for advanced glycation end products (RAGE) is a multiligand receptor that is found on macrophage lineage, cells of vascular origin or cells of the monocyte. It is highly expressed when potential ligands such as inflammatory mediators or HMGB1 are abundantly expressed such as in diabetes disease and cancers [9].

RAGE have an essential role in making a pro-inflammatory microenvironment in the malignant diseases. It could advance the tumor development balance of angiogenesis, metastasis and effective anti-tumor immune response. Because of RAGE is being existed in measurable amounts in blood circulation, HMGB1 and sRAGE could

${ }^{\star}$ Correspondence to: Tarek Aboushousha, Pathology Department, Theodor Bilharz Research Institute, El-Nile Str, Warrak El-Hadar, Embaba, Giza, P.O.Box: 30, Cairo, Egypt, Tel: 00201222186036; E-mail: t.aboushousha@tbri.gov.eg

Key words: bladder cancer, IHC, ER, RAGE, target therapy, expression, bilharziasis Received: October 29, 2018; Accepted: November 16, 2018; Published: November 19, 2018 
utilized easily as clinical biomarkers in monitoring, prediction, staging of cancers and therapy [10].

Estrogen receptor (ER) is one of large family member of nuclear receptor transcription factors with specific domains associated with DNA, transactivation and ligand binding. Estrogen hormones are effective cell growth regulators in wide variety of tissue inside the human body. Effects of Estrogen hormones are mediated through the binding of the two main estrogen subtypes which are ER $\alpha$ and ER $\beta$ [11].

A role for hormonal factors in bladder carcinogenesis has been suggested by the male predominance of UCB diagnoses in industrialized nations independent of tobacco usage or occupational carcinogen exposure. Estrogen plays a role in bladder development and homeostasis and has been implicated in more advanced stage bladder tumors and worse bladder cancer-specific survival among females. Epidemiologic support for a role of estrogen in bladder carcinogenesis includes a $50-60 \%$ increase in UCB diagnoses among females with early menopause, bilateral oophorectomy or absence of combined estrogenprogesterone hormonal replacement therapy [12].

The expression of $\operatorname{ER} \alpha$ and $\operatorname{ER} \beta$ in human tissues have been more uniformly reported across most studies. Only one study has reported lower expression levels of $\mathrm{ER} \alpha$ and $\mathrm{ER} \beta$ in tumor tissues in comparison to benign bladders, with the loss of ER $\alpha$ expression strongly associated with higher stage and grade tumors. The majority of studies observed low to undetectable ER $\alpha$ expression with increased ER $\beta$ expression rates found in almost all human bladder cancer tissues. The ER $\beta$ expression rates reported for human tissue varies widely between $2.5 \%$ and $81 \%$ depending on several intrinsic and technical aspects [13].

\section{Methods}

Our study consists of 64 urinary bladder biopsy specimens. We got tissue sections from their archival material kept in the pathology department of Theodor Bilharz Research Institute (TBRI), Cairo, Egypt. These patients came to TBRI hospital seeking medical advice for their urinary symptoms and were cystoscopically examined and biopsied for histopathological diagnosis.

\section{Immunohistochemical method}

Tissue sections were processed for IHC analysis of RAGE and ER. IHC techniques were carried out on $3 \mu \mathrm{m}$ thick sections. For anti-RAGE IHC, unmasking was performed with $10 \mathrm{mM}$ sodium citrate buffer, $\mathrm{pH}$ 6.0 , at $90^{\circ} \mathrm{C}$ for $30 \mathrm{~min}$. Sections were incubated in $0.03 \%$ hydrogen peroxide for $10 \mathrm{~min}$ at room temperature, to remove endogenous peroxidase activity, and then in blocking serum $(0.04 \%$ bovine serum albumin, A2153, Sigma-Aldrich, Shanghai, China, and 0.5\% normal goat serum X0907, Dako Corporation, Carpinteria, CA, USA, in PBS) for $30 \mathrm{~min}$ at room temperature. Anti-RAGE antibody (A11): sc- 80652 RAGE Antibody (A11) is a mouse monoclonal IgG provided at 200 $\mu \mathrm{g} / \mathrm{ml}$, raised against a truncated extracellular domain of RAGE of human origin (Santa Cruz Biotechnology, USA)

The antibody was used at a dilution of 1:100. The antibody was incubated overnight at $4^{\circ} \mathrm{C}$. Sections were then washed three times for $5 \mathrm{~min}$ in PBS. Non-specific staining was blocked 5\% normal serum for $30 \mathrm{~min}$ at room temperature. Finally, staining was developed with diaminobenzidine substrate and sections were counterstained with hematoxylin. PBS replaced RAGE antibody in negative controls. For ER, nearly the same steps used for RAGE detection were applied with replacement of RAGE Ab by ER $\alpha$ Ab (DAKO, clone EP1, code: IR084/ IS084) which is ready to use and the incubation of sections with ER Ab was shorten for 1 hour only.

\section{Quantification of RAGE and ER expression}

The expression of RAGE was semi quantitatively estimated as the total membrano-cytoplasmic immunostaining scores, which were calculated as the product of a proportion score and an intensity score. The proportion and intensity of staining was evaluated independently. The proportion score reflected the fraction of positive staining cells (score $0:<5 \%$, score 1: $5-10 \%$, score 2: $10-50 \%$, score $3: 50-75 \%$, score 4 : $>75 \%$ ), and the intensity score represented the staining intensity (score 0 : no staining, score 1: weak positive, score 2: moderate positive, score 3: strong positive) [14].

ER expression was considered positive for any nuclear brownish discoloration. The percentage of positive cells was calculated in 3 successive HPF in the maximally positive area of the section. The mean percentage was calculated. The intensity of nuclear positivity was scored as 0 : negative staining, 1: mild intensity, 2: moderate intensity and 3: marked intensity.

\section{Statistical study}

Pearson's Chi square test was used to compare the differences in percentages of positive results between groups. ANOVA and student t-tests were used to compare groups' means. SPSS program of version 20.0 for Windows was used for all statistical analyses. Significant differences between groups were achieved if $(\mathrm{p}<0.05)$.

\section{Results}

The studied cases include; chronic cystitis (6 cases), squamous cell carcinoma (12 cases) and urothelial carcinoma (46 cases).

The majority of studied cases were males (44 cases) with female patients constitute only $31.25 \%$ of cases (10 patients). Age and sex distribution were listed in (Table 1), which showed also the distribution of studied bladder lesions according to tumor grade and bilharzial association.

All cases of squamous cell carcinoma showed high tumor grade and positive muscle invasion, while most cases of urothelial carcinoma were of low-grade malignancy $(65.2 \%)$ and showed negative muscle invasion $(69,6 \%)$. The difference was statistically significant $(\mathrm{p}<0.001)$.

Two thirds of the chronic cystitis cases and half of the squamous cell carcinoma cases were associated with bilharziasis, while only $4.3 \%$ of the urothelial carcinoma cases were positive for bilharziasis. The difference between groups was statistically significant $(\mathrm{p}<0.001)$.

Immunohistochemical study shows significant difference between groups considering the intensity and percentage of cellular expression of RAGE ( $\mathrm{p}<0.01$ and $\mathrm{p}<0.001$ respectively).

Table 1. Distribution of studied bladder lesions according to gender, age, tumor grade and bilharzial association

\begin{tabular}{|c|c|c|c|c|}
\hline \multirow{2}{*}{ Item } & \multirow{2}{*}{ Parameter } & \multicolumn{3}{|c|}{ Histopathological Diagnosis } \\
\cline { 3 - 5 } & Cystitis (6) & SCC (12) & UC (46) \\
\hline Gender & m:f & $4: 2$ & $1: 1$ & $34: 12$ \\
\hline Age & (Mean \pm SD) & $63.5 \pm 1.7$ & $67.8 \pm 5.1$ & $62.5 \pm 6.5$ \\
\hline Tumor Grade & Low: High & - & $0: 12$ & $30: 16$ \\
\hline M. Invasion & $\begin{array}{c}\text { Negative: } \\
\text { Positive }\end{array}$ & - & $0: 12$ & $32: 14$ \\
\hline Bilharziasis & $\begin{array}{c}\text { Negative: } \\
\text { Positive }\end{array}$ & $4: 2$ & $6: 6$ & $44: 2$ \\
\hline
\end{tabular}

SCC: Squamous cell carcinoma; UC: Urothelial carcinoma; f: female; m: male; S.D.: Standard Deviation 
Squamous cell carcinoma showed higher score of RAGE expression compared to both chronic cystitis and urothelial carcinoma, with statistically significant difference ( $\mathrm{p}<0.001$ by ANOVA test).

As regards the ER expression, the higher-most percentage of nuclear positivity was detected in urothelial carcinoma positive cases and the least one was in the single case of SCC. Considering the ER intensity of expression, there was no significant difference between studied cases (Figures 1 and 2).

\section{Urothelial carcinoma (UC)}

High grade urothelial carcinoma showed less ER positive cases (6.25\%) compared to low grade ones (30.0\%). Also, cases without muscle invasion showed more cases of ER positivity compared to muscle invasive tumors (25.0\% and $14.29 \%$ respectively). Papillary urothelial tumors showed more ER expression cases than non-papillary tumors $(23.33 \%$ and $18.75 \%$ respectively). Non-bilharzial associated urothelial tumors showed positive ER expression in 10 out of 44 cases $(22.73 \%)$. Bilharzial association was detected in only 2 urothelial neoplasms. All studied cases of urothelial carcinoma were positive for RAGE expression (100\%) (Table 2) (Figure 3).

\section{Discussion}

The diagnosis of Bladder cancer relies on pathological examination of tumor tissue following endoscopic resection. Despite high specificity,

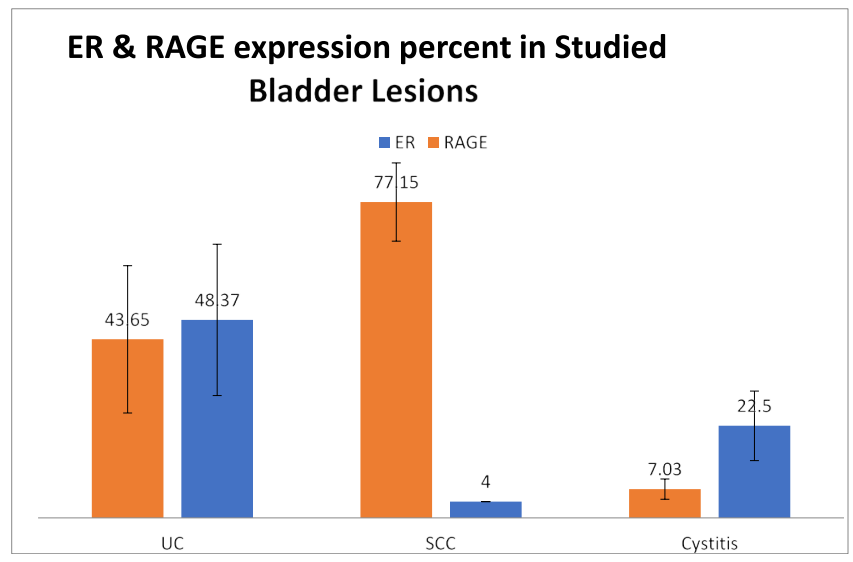

Figure 1. Differences in ER and RAGE expression percent of cellular positivity in studied groups

\section{ER \& RAGE expression intensity in Studied Bladder Lesions}

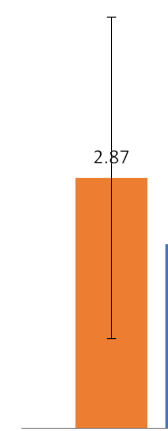

UC $\square$ ER $\square$ RAGE

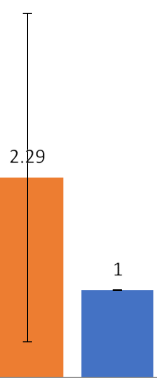

SCC
Table 2. Differences in ER and RAGE positivity in studied urothelial carcinoma cases according to tumor grade, muscle invasion, papillary configuration and bilharzial association

\begin{tabular}{|l|c|c|}
\hline \multicolumn{1}{|c|}{ Grade of tumor } & $\begin{array}{c}\text { ER Positivity } \\
+\mathbf{v e} / \text { Total (\%) }\end{array}$ & $\begin{array}{c}\text { RAGE Positivity } \\
+\mathbf{v e} / \text { Total (\%) }\end{array}$ \\
\hline High & $1 / 16(6.25 \%)$ & $16 / 16(100 \%)$ \\
\hline Low & $9 / 30(30.0 \%)$ & $30 / 30(100 \%)$ \\
\hline P value & $<0.01$ & NS \\
\hline Muscle invasion & $8 / 32(25.0 \%)$ & $32 / 32(100 \%)$ \\
\hline Negative & $2 / 14(14.29 \%)$ & $14 / 14(100 \%)$ \\
\hline Positive & $<0.05$ & $\mathrm{NS}$ \\
\hline P value & $3 / 16(18.75 \%)$ & $16 / 16(100 \%)$ \\
\hline Papillary pattern & $7 / 30(23.33 \%)$ & $30 / 30(100 \%)$ \\
\hline Non-papillary & $<0.05$ & $\mathrm{NS}$ \\
\hline Papillary & \multicolumn{2}{|c|}{} \\
\hline P value & $10 / 44(22.73 \%)$ & $44 / 44(100 \%)$ \\
\hline Bilharziasis & $0 / 2(0.0 \%)$ & $2 / 2(100 \%)$ \\
\hline Negative & - & $\mathrm{NS}$ \\
\hline Positive & & \\
\hline P value & &
\end{tabular}
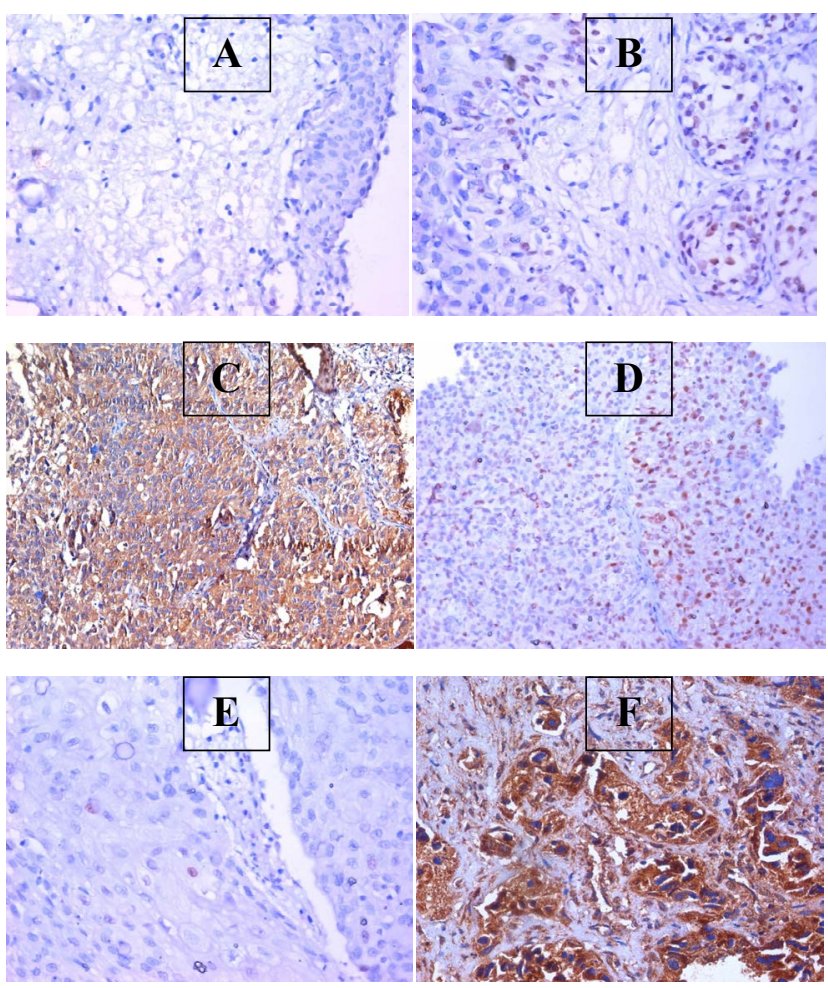

Figure 3. A: Photo of a section in case of chronic cystitis, showing mild expression of RAGE within the urothelium (IHC for RAGE, using DAB, X200); B: Photo of a section in case of chronic cystitis, showing focal positive expression of ER within the urothelium (IHC for ER, using DAB, X200; C: Photo of a section in case of low grade papillary urothelial carcinoma, showing focal expression of ER within the malignant growth (IHC for ER, using DAB, X200); D: Photo of a section in case of low grade, muscle invasive urothelial carcinoma, showing dense diffuse expression of RAGE within the malignant cells (IHC for RAGE, using DAB, X200); E: Photo of a section in case of muscle invasive squamous cell carcinoma, showing infrequent expression of ER within the malignant cells (IHC for ER, using DAB, X200); $\mathbf{F}$. Photo of a section in case of muscle invasive squamous cell carcinoma, showing high expression of RAGE within the malignant cells (IHC for RAGE, using DAB, X200)

urine cytology is not sensitive for the diagnosis of bladder cancer, yet it is widely used for following up [6]. Certainly, suitable molecular diagnostic markers are required for the detection of bladder cancer improvement and then to delay survival of patients [8].

Figure 2. Differences in ER and RAGE expression intensity of cellular positivity in studied groups (SCC: Squamous cell carcinoma; UC: Urothelial carcinoma) 
RAGE is highly expressed in many inflammation-associated cancers [9] like hepatocellular carcinoma [15,16], gastric cancer [17] and breast cancer $[18,19]$.

Estrogen plays a role in bladder development and homeostasis and has been implicated in more advanced stage bladder tumors and worse bladder cancer-specific survival among females. Epidemiologic support for a role of estrogen in bladder carcinogenesis includes a 50$60 \%$ increase in UCB diagnoses among females with early menopause, bilateral oophorectomy or absence of combined estrogen-progesterone hormonal replacement therapy [12].

Estrogens likely exert both stimulatory and inhibitory actions on bladder cancer out growth, which may be cell-specific or dependent on the functional activity of ER $\alpha$ and $E R \beta$.

Recently, Kim et al. demonstrated that raloxifene induces apoptosis in a human bladder cancer cell line, TSU-Pr1, which expresses a high level of ER $\beta$, but not ER $\alpha$, suggesting that $\operatorname{ER} \beta$ may have a role in mediating the apoptotic function of this selective ER modulator (SERM). Collectively, the limited available information suggests that ER $\beta$ may be biologically significant in the bladder [20].

This project was aimed to study the expression of RAGE and ER in bladder cancer patients and to provide better idea about its pathogenesis, aiming to evaluate the possible efficiency of therapy targeting both antigens.

Male patients (54 cases) were more common than female patients (10 patients). Ferlay et al. [21] stated that susceptibility for men are more than four times than women to get bladder cancer. Similarly, Shariat et al. [22] found that diagnosis of bladder cancer found more than four times in men more than women, However, American cancer journal which have statistics in about 74,000 new diagnosed bladder cancer cases in 2015, found that $72 \%$ from these cases are men [23].

In our study, all cases of squamous cell carcinoma showed high tumor grade and were positive for muscle invasion. On the other hand, most cases of urothelial carcinoma were of low-grade malignancy (65.1\%) and showed lack of muscle invasion (70.0\%). The difference was statistically significant $(\mathrm{p}<0.001)$.

Another study that was carried on both non-bilharzial squamous cell carcinoma and transitional cell carcinoma, found that all squamous cell carcinoma cases showed muscle invasion and were at least pT2 [24]. Scosyrev et al. [25] also confirmed that squamous cell carcinoma is more aggressive than urothelial carcinoma.

In our study, two thirds of the chronic cystitis cases and half of the squamous cell carcinoma cases were associated with bilharziasis, while only $4.3 \%$ of the urothelial carcinoma cases were positive for bilharziasis. The difference between both groups was statistically significant $(\mathrm{p}<0.001)$. Similar results were reported by Youssef et al. [26], Mokhtar et al. [27] and Gouda et al. [28].

In our immunohistochemical study, positive RAGE expression was detected in all malignant urinary bladder lesions; both UC and SCC, while it was positive only in $50 \%$ of cystitis cases. We have detected significant difference between benign and malignant bladder lesions considering the intensity and percentage of cellular expression of RAGE $(\mathrm{p}<0.01$ and $\mathrm{p}<0.001$ respectively). Cases of urothelial carcinoma and squamous cell carcinoma showed statistically significant higher levels of RAGE expression compared to cases of cystitis that mostly showed negative and low levels of RAGE expression $(\mathrm{p}<0.001)$. Khorramdelazad et al. [9] showed high expression of genes that encode RAGE in tumor tissues when compared with their normal counterparts. The data that came from their study suggest that RAGE receptor play an important role in the progression of urothelial carcinoma and in the pathogenesis of bladder cancer.

Squamous cell carcinoma showed higher percentage of cellular RAGE expression compared to both chronic cystitis and urothelial carcinoma, with statistically significant difference $(\mathrm{p}<0.001$ by ANOVA test). Pilzweger and Holdenrieder [10] stated that RAGE was found on the surface layer of various epithelial cells and cells of the immune system and this could be a cause of the higher expression of RAGE in squamous cell carcinoma compared to cases of chronic cystitis and urothelial carcinoma.

Our study shows that high grades of urothelial carcinoma, tumors associated with muscle invasion and non-papillary UC showed significantly higher intensity and percentage of RAGE expression compared to their counterparts $(\mathrm{p}<0.001)$. No significant differences were achieved between bilharzial and non-bilharzial associated urothelial carcinoma $(\mathrm{p}>0.1)$. Kuniyasu et al. [29] demonstrated that RAGE is up regulated in higher grade bladder carcinoma compared to lower grade lesions. RAGE expression is examined in a group of gastric carcinoma and found higher reactivity in tumors exhibiting increase in the depth rate of invasion and metastasis.

Du et al. [30] stated that higher expression of RAGE in cancer was not related to the tumor diameter, grade or stage, but it is correlated with the presence of metastasis.

On the contrary, a number of studies have reported that there is a down regulation of RAGE in non-small cell lung carcinomas compared to normal lung tissue [31]. At the same side, Wang et al. [32] confirmed that metastatic NSCLC lesions showed decreased RAGE compared to the primary tumors. These investigators proposed that RAGE may have a putative tumor suppressor function in normal lung tissues.

As regards the ER expression, the highest percentage of nuclear positivity was detected in urothelial carcinoma cases and the lowest one was in the single case of SCC. Considering the ER intensity of expression, there was no significant difference between both studied groups.

High grade urothelial carcinoma showed less ER positive cases (6.25\%) compared to low grade ones (30.0\%). Also, cases without muscle invasion showed more cases of ER positivity compared to muscle invasive tumors ( $25.0 \%$ and $14.29 \%$ respectively).

Papillary urothelial tumors showed more ER expression cases than non-papillary tumors ( $23.33 \%$ and $18.75 \%$ respectively). The expression of $\operatorname{ER} \alpha$ and $\operatorname{ER} \beta$ in human tissues have been more uniformly reported across most studies. Only one study has reported lower expression levels of $\mathrm{ER} \alpha$ and $\mathrm{ER} \beta$ in tumor tissues in comparison to benign bladders, with the loss of ER $\alpha$ expression strongly associated with higher stage and grade tumors. The majority of studies observed low to undetectable ER $\alpha$ expression with increased ER $\beta$ expression rates found in almost all human bladder cancer tissues. The ER $\beta$ expression rates reported for human tissue varies widely between $2.5 \%$ and $81 \%$ depending on several intrinsic and technical aspects [13]. Hoffman et al. [33] demonstrated that raloxifene induces apoptosis in a human bladder cancer cell line, TSU-Pr1, which expresses a high level of ER $\beta$, but not ER $\alpha$, suggesting that $\operatorname{ER} \beta$ may have a role in mediating the apoptotic function of this selective ER modulator (SERM).

In our study, non-bilharzial associated urothelial tumors showed positive ER expression in 10 out of 44 cases (22.73\%). Bilharzial association was detected only in 2 urothelial neoplasms. 


\section{Conclusion}

According to the results of the current preliminary study, RAGE and ER might be helpful as potential targets for molecular based therapeutic strategies in the prevention or management of bladder cancer. Working on larger sample size could validate and confirm our results.

\section{References}

1. Siegel R, Naishadham D, Jemal A (2013) Cancer statistics, 2013. CA Cancer J Clin 63: 11-30. [Crossref]

2. Compérat E, Larré S, Roupret M, Neuzillet Y, Pignot G, et al. (2015) Clinicopathological characteristics of urothelial bladder cancer in patients less than 40 years old. Virchows Arch 466: 589. [Crossref]

3. Gouda I, Mokhtar N, Bilal D, El-Bolkainy T, El-Bolkainy NM (2007) Bilharziasis and bladder cancer: a time trend analysis of 9843 patients. J Egypt Natl Canc Inst 19: 158162. [Crossref]

4. van Osch FH, Jochems SH, van Schooten FJ, Bryan RT, Zeegers MP (2016) Quantified relations between exposure to tobacco smoking and bladder cancer risk: a metaanalysis of 89 observational studies. Int J Epidemiol 45: 857. [Crossref]

5. Ramirez D, Gupta A, Canter D, Harrow B, Dobbs RW, et al. (2016) Microscopic haematuria at time of diagnosis is associated with lower disease stage in patients with newly diagnosed bladder cancer. BJU Int 117: 783-786. [Crossref]

6. Szarvas T, Nyirády P, Ogawa O, Furuya H, Rosser CJ, et al. (2018) Urinary protein markers for the detection and prognostication of urothelial carcinoma. Methods $\mathrm{Mol}$ Biol 1655: 251-273. [Crossref]

7. El Gendy H, Madkour B, Abdelaty S, Essawy F, Khattab D, et al. (2015) Galectin 3 for the diagnosis of bladder cancer. Arab J Urol 12: 178-181. [Crossref]

8. Shariat SF, Karam JA, Lotan Y, Karakiewizc PI (2008) Critical evaluation of urinary markers for bladder cancer detection and monitoring. Rev Urol 10: 120-135. [Crossref]

9. Khorramdelazad H, Bagheri V, Hassanshahi G, Karami H, Moogooei M, et al. (2015) S100A12 and RAGE expression in human bladder transitional cell carcinoma: a role for the ligand/RAGE axis in tumor progression? Asian Pac J Cancer Prev 16: 27252729. [Crossref]

10. Pilzweger C, Holdenrieder S (2015) Circulating HMGB1 and RAGE as clinical biomarkers in malignant and autoimmune diseases. Diagnostics 5: 219-253. [Crossref]

11. Yaşar P, Ayaz G, User SD, Güpür G, Muyan M (2017) Molecular mechanism of estrogen-estrogen receptor signaling. Reprod Med Biol 16: 4-20. [Crossref]

12. Kauffman EC, Robinson BD, Downes M, Marcinkiewicz K, Vourganti S, et al. (2013) Estrogen receptor- $\beta$ expression and pharmacological targeting in bladder cancer. Oncol Rep 30: 131-138. [Crossref]

13. Godoy G, Gakis G, Smit CL, Fahmy O (2016) Effects of androgen and estrogen receptor signaling pathways on bladder cancer initiation and progression. Bladder Cancer 2: 127-137. [Crossref]

14. Xu XC, Abuduhadeer X, Zhang WB, Li T, Gao H, et al. (2013) Knockdown of RAGE inhibits growth and invasion of gastric cancer cells. Eur J Histochem 57: e36. [Crossref]

15. Aboushousha T, Mamdouh S, Hamdy H, Helal N, Khorshed F, et al. (2018) Immunohistochemical and biochemical expression patterns of TTF-1, RAGE, GLUT-1 and SOX2 in HCV-associated hepatocellular carcinomas. Asian Pac J Cancer Prev 19: 219-227. [Crossref]

16. Aboushousha T, Essam N, Ageez A', Helal N, Badawy A (2017) RAGE expression in HCV-related hepatocellular carcinoma; comparison between malignant and perimalignant tissues. Int J Dev Res 7: 10962-10967.

17. Aboushousha T, Badawy A, Moussa M, Omran Z, Helmy AH, et al. (2016) Evaluation of RAGE (Receptor for advanced glycation end-products) expression in gastric carcinoma of Egyptian patients in relation to helicobacter pylori infection. Ann Path Lab Med 3.

18. Pan H, He L, Wang B, Niu W (2014) The relationship between RAGE gene four common polymorphisms and breast cancer risk in northeastern Han Chinese. Sci Rep 4: 4355 .

19. Aboushousha T, Hammam O, Safwat G, Eesa A, Ahmed S, et al. (2018) Differential expression of RAGE, EGFR and Ki-67 in primary tumors and lymph node deposits of breast carcinoma. Asian Pac J Cancer Prev 19: 2269-2277. [Crossref]
20. Shen SS, Smith CL, Hsieh JT, Yu J, Kim IY, et al. (2006) Expression of estrogen receptors- $\alpha$ and $-\beta$ in bladder cancer cell lines and human bladder tumor tissue. Cancer 106: 2610-2616. [Crossref]

21. Ferlay J, Soerjomataram I, Ervik M, Dikshit R, Eser S, et al. (2015) Cancer incidence and mortality worldwide. Int J Cancer 136: 989-1243.

22. Shariat SF, Sfakianos JP, Droller MJ, Karakiewicz PI, Meryn S, et al. (2010) The effect of age and gender on bladder cancer: a critical review of the literature. BJU Int 105: 300-308. [Crossref]

23. McIntosh J (2016) Bladder cancer: causes, symptoms and treatments. Medical News Today 5: 13-38.

24. Rausch S, Hofmann R, Knobloch R (2012) Non-bilharzial squamous cell carcinoma and transitional cell carcinoma with squamous differentiation of the lower and upper urinary tract. Urol Ann 4: 14. [Crossref]

25. Scosyrev E, Yao J, Messing E (2009) Urothelial carcinoma versus squamous cel carcinoma of bladder: is survival different with stage adjustment? Urology 73: 822827. [Crossref]

26. Youssef R, Kapur P, Kabbani W, Shariat S, Mosbah A, et al. (2010) Bilharzial vs non-bilharzial related bladder cancer: pathological characteristics and value of cyclooxygenase-2 expression. BJU Int 108: 31-37. [Crossref]

27. Mokhtar N, El Bolkainy N, Khaled H, Zekri A (2016) The pathobiology of bilharziaassociated bladder cancer. Medical Sciences 1.

28. Gouda I, Mokhtar N, Bilal D, El-Bolkainy T, El-Bolkainy NM (2007) Bilharziasis and bladder cancer: a time trend analysis of 9843 patients. J Egypt Natl Canc Inst 19: 158162. [Crossref]

29. Kuniyasu H, Oue N, Wakikawa A, Shigeishi H, Matsutani N, et al. (2002) Expression of receptors for advanced glycation end-products (RAGE) is closely associated with the invasive and metastatic activity of gastric cancer. J Pathol 196: 163-170. [Crossref]

30. Du X, Fu X, Hao Q (2007) Expression and clinical significance of HMGB1 and RAGE in cervical carcinoma. Chinese Journal of Clinical Oncology 4: 343-346.

31. Bartling B, Demling N, Silber RE, Simm A (2006) Proliferative stimulus of lung fibroblasts on lung cancer cells is impaired by the receptor for advanced glycation endproducts. Am J Respir Cell Mol Biol 34: 83-91. [Crossref]

32. Wang T, Huo X, Chong Z, Khan H, Liu R, et al. (2018) A review of S100 protein family in lung cancer. Clin Chim Acta 476: 54-59. [Crossref]

33. Hoffman KL, Lerner SP, Smith CL (2013) Raloxifene inhibits growth of RT4 urothelial carcinoma cells via estrogen receptor-dependent induction of apoptosis and inhibition of proliferation. Horm Cancer 4: 24-35. [Crossref]

Copyright: (C2018 Aboushousha T. This is an open-access article distributed under the terms of the Creative Commons Attribution License, which permits unrestricted use, distribution, and reproduction in any medium, provided the original author and source are credited. 